\title{
Hubungan Body Shaming Terhadap Keadaan Self Confidence Remaja
}

Fatmawati $^{1}$, Afrizawati ${ }^{2}$, Miftahuddin ${ }^{3}$, Suhaimi $^{4}$, M. Fahli Zatrahadi ${ }^{5}$, Darmawati ${ }^{6}$, Anisa Siti Nurjanah ${ }^{7}$

${ }^{1}$ Universitas Islam Negeri Sultan Syarif Kasim Riau

${ }^{2}$ Universitas Islam Negeri Sultan Syarif Kasim Riau

${ }^{3}$ Universitas Islam Negeri Sultan Syarif Kasim Riau

${ }^{4}$ Universitas Islam Negeri Sultan Syarif Kasim Riau

${ }^{5}$ Universitas Islam Negeri Sultan Syarif Kasim Riau

${ }^{6}$ Universitas Islam Negeri Sultan Syarif Kasim Riau

${ }^{7}$ Universitas Negeri Yogyakarta

\begin{tabular}{|c|c|}
\hline Article Info & ABSTRACT \\
\hline Article history: & $\begin{array}{l}\text { Body shaming includes verbal acts of violence because negative comments } \\
\text { made by perpetrators about a person's body shape can hurt the victim's }\end{array}$ \\
\hline Received Dec $12^{\text {th }}, 2021$ & heart and thus impair his confidence, as researchers found in this study that \\
\hline Revised Feb 20 ${ }^{\text {th }}, 2021$ & most of them experience body shaming treatment and this treatment makes \\
\hline Accepted Apr $26^{\text {th }}, 2021$ & them less confident. This study aims to examine the relationship of body \\
\hline Keyword: & $\begin{array}{l}\text { measuring the relationship between independent variables and dependent } \\
\text { variables. The sample was taken from members of the tiku student }\end{array}$ \\
\hline $\begin{array}{l}\text { Body Shaming, Self Confidence, } \\
\text { Kepercayaan Diri }\end{array}$ & $\begin{array}{l}\text { association using a convenience technique consisting of } 50 \text { respondents. } \\
\text { The instrument in this study uses cross sectional study design with pearson } \\
\text { product moment correlation analysis in Statistical Product and Service } \\
\text { Solutionsprogram. The results obtained from this study show that there is a } \\
\text { strong relationship between body shaming to confidence in the student } \\
\text { association tiku district of West Sumatra. }\end{array}$ \\
\hline
\end{tabular}

Corresponding Author:

Fatmawati,

Universitas Islam Negeri Sultan Syarif Kasim Riau

Email: Fatmawati@uin-suska.ac.id

\section{Introduction}

Mengomentari bentuk tubuh orang lain dikenal dengan sebutan body shaming (Rismajayanthi and Priyanto 2019), hal ini erat kaitannya dengan anggapan seseorang terhadap bentuk tubuh yang menjadi standar ideal dalam masyarakat (Ottesen n.d.). Body shaming termasuk bagian kekerasan secara verbal karena ucapan yang disampaikan pelaku itu dapat melukai hati korbannya (Putri, Kuntjara, and Sutanto 2018) dan tindakan ini dapat terjadi secara langsung dalam kehidupan (Briliantari and Darmadi n.d.).

Perlakuan body shaming dengan mengolok-olok bentuk tubuh seseorang seolah-olah dianggap sebagai hal yang normal dan dapat diterima dalam masyarakat (Kar 2019), padahal tindakan ini dapat berdampak negatif terhadap korban body shaming yaitu dapat mempengaruhi kondisi mental dan sosial seseorang (Lestari 2019), yang diantaranya membuat korban memiliki 
penilaian yang buruk terhadap dirinya sendiri sehingga korban menjadi tidak percaya diri (Hidayat, Malfasari, and Herniyanti 2019).

Biasanya orang yang memiliki bentuk tubuh yang berbeda mereka cenderung tidak confidence (Hidayat et al. 2019), hal ini dikarenakan adanya persepsi yang muncul dalam diri seseorang bahwa dia tidak memenuhi sesuatu yang menjadi standar ideal dalam masyarakat (Lind and Elíasdóttir 2016), sehingga muncul ketakutan dalam dirinya bahwa keberadaannya tidak diterima dalam lingkungan masyarakat dan akan menjadi target korban dari body shaming (Pelayanan et al. 2019), hal ini dapat mengganggu kepercayaan diri seseorang dalam beradaptasi dengan lingkungannya. Kepercayaan diri merupakan variabel yang mempengaruhi banyak aspek dalam kehidupan seseorang mulai dari memilih tujuan, pengambilan keputusan dan merupakan modal bagi seseorang untuk dapat menyelesaikan masalah yang dihadapi (Waini et al. 2014), termasuk masalah menjadi korban body shaming, dengan kata lain, proses kognitif, emosi, motivasi, pengambilan keputusan dan pilihan, adalah hasil dari kepercayaan diri seseorang (Amini et al. 2014).

Seseorang yang memiliki gangguan kepercayaan diri cenderung mengalami masalah dalam menyelesaikan persoalan dalam hidupnya (Jones 2017). Terganggunya kepercayaan diri seseorang akan berdampak pada kehidupannya (Liashenko n.d.), karena kepercayaan diri ini mengacu pada sikap dan keyakinan terhadap diri sendiri dan bagaimana seseorang menerima pesan-pesan sosial dari lingkungannya, apabila lingkungannya mengirimkan pesan-pesan negatif maka dianggap dapat menurunkan tingkat kepercayaan diri seseorang (Al-Hebaish 2012).

Manusia sebagai makhluk sosial tidak lepas dari interaksi dengan manusia lain, dari interaksi yang terjadi terkadang secara sengaja ataupun tidak sengaja individu memberikan komentar bentuk tubuh terhadap individu yang lain, ini akan menjadi masalah bagi orang yang dikomentari apabila dia tidak siap secara mental menerima komentar dari orang lain dan itu dapat mempengaruhi kepercayaan dirinya (Zatrahadi, Darmawati, and Yusra 2021). Seharusnya seseorang mampu mempertahankan bahkan meningkatkan kepercayaan dirinya karena dengan adanya kepercayaan diri yang kuat seseorang bisa menyelesaikan semua rintangan yang dihadapi sehingga mampu meminimalisir ketakutan sosial salah satunya ketakutan menjadi korban body shaming, agar memiliki kemampuan untuk menjalin kontak dengan lingkungan sekitar. Oleh karena itu penting bagi seseorang untuk dapat meningkatkan kepercayaan dirinya agar mampu beradaptasi dengan baik dalam ligkungannya.

Orang yang menjadi korban body shaming dan terlalu berfikir keras dalam memikirkan bentuk tubuhnya yang dianggap bermasalah dapat mengganggu kesehatan fisiknya dikarenakan sikapnya yang tidak lagi memperdulikan kesehatannya sehingga memperburuk kondisi fisiknya (Lind and Elíasdóttir 2016). Pengalaman body shaming juga dialami oleh remaja perempuan dikarenakan bentuk tubuhnya yang gemuk, hitam, dan berjerawat, mereka sensitif pada hal-hal yang berhubungan dengan tubuh dan cenderung menutup diri dari lingkungannya (Fauzia and Rahmiaji 2019). Hal demikian juga terlihat dalam ikatan mahasiswa tiku (IMT) di kecamatan tanjung mutiara kabupaten agam sumatera barat. Dimana banyak dari mahasiswa yang mengeluh karena mendapatkan perlakuan body shaming dari teman-temannya, sehingga mengakibatkan korban kehilangan kepercayaan diri dan tidak mau betemu dengan teman-teman yang lain dikarenakan belum siap untuk menghadapi komentar-komentar negatif mengenai bentuk tubuhnya dan merasa malu saat beradaptasi dengan lingkungannya, oleh karena itu peneliti tertarik untuk melakukan penelitian mengenai hal ini.

Penelitian ini bertujuan untuk meneliti hubungan antara body shaming terhadap self confidence karena peneliti melihat adanya hubungan body shaming terhadap kepercayaan diri seseorang, khususnya pada ikatan mahasiswa tiku kecamatan tanjung mutiara kabupaten agam, sumatera barat. 


\section{Method}

Penelitian ini merupakan penelitian kuantitatif dengan pendekatan cross sectional, karena variable yang hendak diteliti antara yang satu dengan yang lain diukur dalam satu waktu (priyono 2016), peneliti mencoba mengungkap hubungan variable independen dengan variable depeden dari populasi yang hendak diteliti dengan tujuan untuk mengetahui korelasi faktor resiko dari independen dengan efek dari dependen. Penelitian ini dilakukan pada ikatan mahasiswa tiku kabupaten Agam Sumatera Barat.

Karena keterbatasan waktu dan biaya tidak memungkinkan peneliti untuk menyebarkan angket sacara merata oleh karena itu disini peneliti menggunakan google form dalam menyebarkan angket dan menggunakan teknik convenience sampling dalam pengambilan sampel, dimana sampel dipilih dari orang yang paling mudah diakses sehingga peneliti memperoleh 50 responden dari angket yang telah disebarkan. Kuesioner dalam penelitian ini menggunakan skala likert yang dibagi menjadi dua instrument, pertama terdiri 11 item pernyataan untuk variabel $\mathrm{X}$ dan yang ke dua terdiri dari 15 item pernyataan untuk variabel $\mathrm{Y}$, setiap pernyataan terdiri dari lima pilihan bobot yaitu Sangat Setuju (SS), Setuju (S), Ragu-ragu (RG), Tidak Setuju (TS) dan Sangat Tidak Setuju (STS).

Setelah data diperoleh selanjutnya data akan diolah menggunakan program SPSS untuk memudahkan peneliti dalam menganalisis data. Penelitian ini menggunakan beragam jenis analisis dalam program SPSS untuk peninjauan seperti validitas dan reliabilitas guna menunjukan kevalidan suatu instrument dan menunjukan bahwa instrument dapat dipercaya selanjutnya menggunakan analisis korelasi pearson product moment (PPM) untuk mengukur hubungan variabel dependen dan variabel independen. Analisis korelasi PPM ini bertujuan untuk mengetahui hubungan antar variabel dan variable ini dapat dikatakan berkorelasi jika perubahan variabel yang satu mempengaruhi variabel yang lain, peneliti menggunakan korelasi ini dikarenakan cara ini lebih cocok untuk meneliti hubungan antara variabel independen dan variabel dependen dari populasi yang hendak diteliti.

\section{Results and Discussions}

Setelah dilakukan uji validitas pada 11 item instrument variabel $\mathrm{X}$ diperoleh hasil bahwa 11 instrumen tersebut dinyatakan valid. Valid tidaknya suatu instrument dapat dilihat dari nilai $r$ hitung dan $r$ tabel pada taraf 5\% ( $n-1=50-1=49)$. Jika $r$ hitung lebih besar dari $r$ tabel maka instrument dinyatakan valid dan sebaliknya jika $r$ hitung lebih kecil dari tabel maka istrumen dinyatakan tidak valid.

Pada tabel uji reliability variabel $\mathrm{X}$ di atas dapat dilihat nilai cronbach's alpha $=0,844$ dan nilai $r$ tabel $=0,281$ dengan derajat kebebasan $(\mathrm{dk}=\mathrm{n}-1=50-1=49)$ pada taraf 5\%. Sesuai dengan kaidah pengambilan keputusan Instrument dinyatakan reliable karena nilai cronbach's alpha lebih besar nilai $r$ table. Pada 15 item pernyataan variabel Y setelah dilakukan uji validitas 15 penyataan tersebut dinyatakan valid. Kevalidan suatu instrument dapat dilihat dari nilai $r$ hitung dan $r$ tabel pada taraf 5\% ( $n-1=50-1=49)$. Jika $r$ hitung $\geq$ dari $r$ tabel maka instrument dinyatakan valid dan sebaliknya jika $r$ hitung $\leq$ dari $r$ tabel maka istrumen dinyatakan tidak valid.

Nilai Cronbach's Alpha diperoleh pada uji reliability variabel $Y=0,808$ dan nilai $r$ tabel= 0,28 dengan derajat kebebasan $(\mathrm{dk}=\mathrm{n}-1=50-1=49)$. Instrument dinyatakan reliable karena nilai cronbach's alpha lebih besar dari nilai $r$ table. Berikut merupakan hasil data yang telah diolah peneliti menggunakan teknik korelasi product moment untuk mengukur hubungan antara variabel $\mathrm{X}$ dan variabel $\mathrm{Y}$. 
Tabel I.

Correlations

\begin{tabular}{|llrr|}
\hline & & Body shaming & Self confidence \\
\hline Body shaming & Pearson Correlation & 1 & .559 \\
& Sig. (2-tailed) & & .000 \\
& $\mathrm{~N}$ & 50 & 50 \\
Self confidence & Pearson Correlation & $.559^{* \pi}$ & 1 \\
& Sig. (2-tailed) & .000 & \\
& $\mathrm{~N}$ & 50 & 50 \\
\hline$* *$ Correlation is significant at the 0.01 level (2-tailed). & & \\
\end{tabular}

Dari data yang telah diolah menggunakan korelasi pearson product moment diperoleh bahwa terdapat hubungan antara body shaming terhadap self confidence. Ternyata $0,05>0.005$, maka Ho ditolak dan $\mathrm{Ha}$ diterima artinya terdapat hubungan yang signifikan antara body shaming terhadap self confidence. Temuan pada penelitian ini yang dilakukan pada ikatan mahasiswa tiku kabupaten agam sumatera barat diperoleh hasil bahwa terdapat hubungan antara body shaming terhadap self confidence. Body shaming berdampak negatif terhadap korbannya yaitu dapat mempengaruhi kondisi mental karena komentar negatif yang diterima mengenai bentuk tubuhnya membuat korban memiliki penilaian yang buruk terhadap dirinya sendiri dan hal ini mengganggu kepercayaan dirinya dalam beradaptasi dengan lingkungan.

Berdasarkan hasil pengukuran yang telah dilakukan pada 50 responden yang telah diolah dengan teknik korelasi product moment terlihat pada hasil penelitian pada cara 1 menunjukkan nilai probabilitas $(0,05)$ lebih besar dari nilai sig $(0.005)$ dan pada cara 2 menunjukkan nilai $r$ hitung (0.559) lebih besar dari nilai $r$ tabel (0.284), dari hasil pengukuran tersebut membuktikan bahwa terdapat hubungan yang signifikan antara body shaming dengan self confidence. Berbeda dengan penelitian yang telah dilakukan oleh Jean M. Lamont (2015) yang menyatakan bahwa body shaming dapat memperburuk kesehatan fisik korbannya, adanya sikap negatif terhadap proses tubuh sehingga mengurangi penilaian terhadap kesehatannya dan pada akhirnya berdampak pada kesehatan fisiknya.

\section{Conclusions}

Ikatan mahasiswa tiku yang menjadi responden pada penelitian ini menunjukkan bahwa sebagian besar mereka mendapat perlakuan body shaming dan ditemukan bahwa perlakuan body shaming ini berdampak buruk bagi korbannya dikarenakan ketidaksiapan mentalnya dalam menerima perlakuan ini. Perlakuan Body shaming dapat mempengaruhi kepercayaan diri korbannya, terganggunya kepercayaan diri ini berdampak pada kehidupan seseorang diantaranya membuat korban malu karena bentuk tubuhnya mendapat ejekan dari orang lain dan membuatnya menutup diri dari lingkungan sehingga korban mengalami kesulitan untuk dapat berfungsi secara normal dalam kehidupan bermasyarakat. Pada penelitian ini diperoleh hasil dari olahan data yang telah diolah menggunakan. SPSS dengan menggunakan teknik korelasi product moment bahwa terdapat hubungan yang signifikan antara variabel body shaming (X) terhadap variabel self confidence $(\mathrm{Y})$.

\section{References}

Al-Hebaish, Safaa Mohammad. 2012. "The Correlation between General Self-Confidence and Academic Achievement in the Oral Presentation Course." Theory and Practice in Language Studies 2(1):60-65. doi: 10.4304/tpls.2.1.60-65.

Amini, Leila, M. Sc, Kobra Valian, M. Sc, Homa Sdeghi Avvalshahr, M. Sc, Ali Montaeri, and D. Ph. 2014. "Self-Confidence in Women with and without Polycystic Ovary Syndrome." 8(3):113-16. 
Briliantari, Ni Putu Melinia Ary, and A. A. Ngurah Oka Yudistira Darmadi. n.d. "mediasi penal sebagai alternatif penyelesaian perkara pada tindak pidana body shaming." Kertha Wicara: Journal Ilmu Hukum 8(8):1-15.

Fauzia, Tri Fajariani, and Lintang Ratri Rahmiaji. 2019. "Memahami Pengalaman Body Shaming Pada Remaja Perempuan P.” Interaksi Online 7(3):238-48.

Hidayat, Rahmad, Eka Malfasari, and Rina Herniyanti. 2019. "Hubungan Perlakuan Body Shaming Dengan Citra Diri Mahasiswa." Jurnal Keperawatan Jiwa 7(1):79-86.

Jones, T. O. M. 2017. “Self- Confidence In Henry Fielding' s.” 1(1):141-62.

Kar, Partha. 2019. "Partha Kar: Dieting and Body Shaming." 1222(March):2019. doi: 10.1136/bmj.11222.

Lestari, Sumi. 2019. "Bullying or Body Shaming? Young Women in Patient Body Dysmorphic Disorder." PHILANTHROPY: Journal of Psychology 3(1):59. doi: 10.26623/philanthropy.v3i1.1512.

Liashenko, O. n.d. “УДК 159.9 С. К. Мельничук.” 191-96.

Lind, Eva, and Fells Elíasdóttir. 2016. "ILind, E., \& Elíasdóttir, F. (2016). Is Body Shaming Predicting Poor Physical Health and Is There a Gender Difference ? BSc in Psychology.s Body Shaming Predicting Poor Physical Health and Is There a Gender Difference ? BSc in Psychology."

Ottesen, Ida. n.d. "Body Love and Body Shaming: An Analysis of Meghan Trainor's All About That Bass and Mary Lambert's Body Love, Part 1+ 2."

Pelayanan, Jurnal, Kepada Masyarakat, Tristanti Puspitasari, Farah Farida Tantiani, and Wishnu Wardhana. 2019. "Upaya Peningkatan Body Acceptance Baseline Melalui Gerakan Say No To Body Shaming Di Kalangan Pelajar.” 1(2):110-19.

priyono. 2016. Metode Penelitian Kuantitatif. edited by Teddy Chandra. surabaya.

Putri, Brigitta Anggraeni Stevany, Aristarchus Pranayama Kuntjara, and Ryan Pratama Sutanto. 2018. "Perancangan Kampanye 'Sizter's Project' Sebagai Upaya Pencegahan Body Shaming." Jurnal DKV Adiwarna 1(12):9.

Rismajayanthi, Ni Gusti Agung Ayu Putu, and I. Made Dedy Priyanto. 2019. "Tinjauan Yuridis Terhadap Tindak Pidana Penghinaan Citra Tubuh (Body Shaming) Menurut Hukum Pidana Indonesia." Kertha Wicara: Journal Ilmu Hukum 1-16.

Waini, Iskandar, Khairum Hamzah, Rahaini Mohd, Nor Hamizah, and Nurul Amira. 2014. "SelfConfidence in Mathematics: A Case Study on Engineering Technology Students in FTK , UTeM." 2:10-13.

Zatrahadi, M. Fahli, Darmawati Darmawati, and Ninda Nofila Yusra. 2021. "The Effect of Online Game Addiction on Adjustment Social in Adolescents." Indonesian Journal of Creative Counseling 1(1):15-19. 